\title{
Use of a National Electronic Health Record Network to Describe Characteristics and Healing Patterns of Sickle Cell Ulcers
}

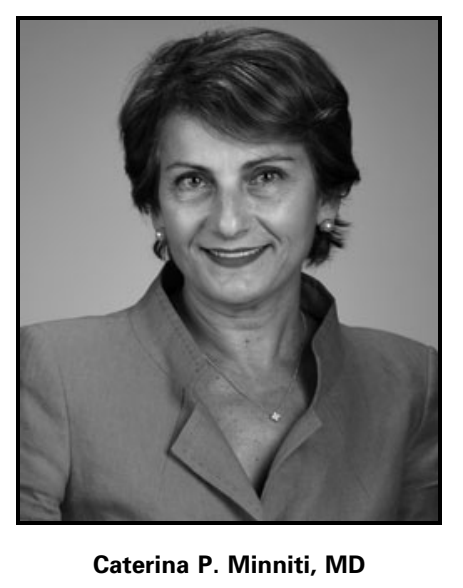

Submitted for publication April 26, 2018. Accepted in revised form June 10, 2018.

${ }^{*}$ Correspondence: Division of Hematology, Montefiore Medical Center, Bronx, NY 10467 (e-mail: cminniti@montefiore.org).

\author{
Anna Flattau, Hanna Gordon, Giacomo Vinces, \\ William J. Ennis, ${ }^{3}$ and Caterina P. Minniti ${ }^{4, *}$ \\ ${ }^{1}$ Department of Family and Social Medicine, Wound Healing Program, Montefiore Medical Center, Bronx, New York. \\ ${ }^{2}$ Healogics, Inc., Jacksonville, Florida. \\ ${ }^{3}$ Department of Surgery, Section of Wound Healing and Tissue Repair, University of Illinois Hospital and Health Sciences \\ System, Chicago, Illinois. \\ ${ }^{4}$ Division of Hematology, Montefiore Medical Center, Bronx, New York.
}

Objective: Sickle cell ulcers affect as many as $15 \%$ of patients with sickle cell disease in the United States and severely impact quality of life. An understanding of baseline healing patterns is important to inform study design for future trials that test therapies for this disease.

Approach: In this study, an electronic wound management system was leveraged to analyze retrospective data on 133 unique sickle cell patients who were treated across 114 wound healing centers, and to describe their characteristics and healing patterns as compared with those of venous ulcer patients. The data included 198 care episodes for 427 wounds.

Results: Patients with sickle cell ulcers were younger and had fewer comorbid diseases than those with venous ulcers. Larger size and longer duration were predictors of poor healing. Between the first and fourth assessments, mean change in area for sickle cell ulcers showed a 58\% increase, compared with a $13 \%$ decrease for venous ulcers. Kaplan-Meier curves showed poorer healing in sickle cell ulcers than in venous ulcers across all categories of size and duration. Patients with sickle cell ulcers had longer care episodes and were more likely to re-present for care.

Innovation: This study reports on the largest data set of sickle cell ulcer patients analyzed to date in the published literature to provide a more detailed understanding of wound healing patterns of this disease.

Conclusion: A national network of electronic health records can effectively identify a large number of patients with sickle cell ulcers to support analysis of epidemiology, healing patterns, and health care utilization.

Keywords: leg ulcers, sickle cell disease, venous ulcers, chronic wounds, healing

\section{INTRODUCTION}

As TREATMENT OF PEDIATRIC sickle cell disease has advanced, most patients with sickle cell disease in resource-rich countries reach adulthood. ${ }^{1}$ An aging sickle cell population suffers from numerous chronic complications that arise in the late adolescent years and fully manifest in adulthood, including sickle cell ulcers, which are estimated to occur in $\sim 5-25 \%$ of patients with sickle cell disease in the United States. ${ }^{2-6} \mathrm{Di}$ agnosis is made by identifying a leg, ankle, or dorsal foot ulcer in the context of sickle cell disease. Clinical features typically include a painful ulcer with a punched-out appearance 
with slough, located on the leg, ankle, or dorsum of the foot. ${ }^{4}$ Sickle cell ulcers may be similar in appearance to other types of leg ulcers, such as venous stasis ulcers or ulcers associated with rheumatic disease.

Sickle cell ulcers have not received much attention in the literature until recently, perhaps because their frequency, severity, and impact on quality of life and pain management had not been fully appreciated. ${ }^{7,8}$ Moreover, little is known about the pathophysiology, clinical evolution, and healing patterns of sickle cell ulcers. ${ }^{9,10}$ Sickle cell ulcers are often approached with treatment pathways that have been shown to be effective in venous ulcers, which are the most common type of leg ulcers in a general population. However, these treatments have not been proven effective in sickle cell ulcers. ${ }^{9,11}$ An understanding of baseline healing patterns of sickle cell ulcers is important to inform study design for future trials that test therapies specific to this disease.

\section{CLINICAL PROBLEM ADDRESSED}

A major barrier to studying sickle cell patients is the difficulty in obtaining a large enough sample for descriptive or comparative analysis. Although ulcers are relatively common in sickle cell patients, data systems in hematology clinics do not typically capture wound-related data in a format that can be analyzed. Previous studies of large data sets relied on cohorts of patients who were referred to highvolume specialist centers, and may not represent the epidemiology or disease course of sickle cell ulcers treated in diverse settings. ${ }^{7,12}$ As information systems evolve across the health delivery system, large clinical databases used by networks of clinical providers can be a promising tool for the study of disease entities that are relatively rare at any single treatment center. ${ }^{13,14}$

In this study, we leveraged a clinical information system used by a national network of wound healing centers in the United States to describe the characteristics of sickle cell ulcers in this broad population; examine the effect of clinical characteristics on healing prognosis; and identify healing patterns of sickle cell ulcers as distinct from those of venous ulcers, which are the most common type of lower limb wound.

\section{MATERIALS AND METHODS}

Data were extracted from i-heal ${ }^{\circledR}$, a proprietary wound management system used by 794 outpatient wound care centers throughout the United States that are managed by a wound care management company, Healogics (Healogics, Inc., Jacksonville, FL). The time frame for data inclusion, from January 2014 to April 2016, was determined by the availability of aggregate wound data at the time of analysis.

Of the 794 centers, just $>50 \%$ maintained a complete patient record within i-heal as the primary source of clinical documentation for the wound center. The remaining centers used paper documentation systems for clinical care records and entered a more limited set of data into i-heal for performance management purposes. In the analysis, we distinguish between the full sample analysis, which includes patients from all wound centers, and subsample analyses, which are limited to the centers that maintained complete patient records within i-heal and thus provided more detailed data. The choice of whether to enter all patient data into i-heal was made by individual centers based on factors such as local preferences and presence of pre-existing general electronic systems.

The analysis was limited to patient care episodes in which the patient had at least one wound clinically diagnosed as a venous ulcer or sickle cell ulcer, as documented on a drop-down menu of wound diagnoses within i-heal. Wounds were excluded as qualifying diagnoses if the relevant visit was documented as "consultation only" (which denotes a one-time visit), or if the center did not have at least one follow-up visit 8 days or more after initial presentation, to ensure that all of the included patients had follow-up within the centers. In addition, wounds were excluded if the wound location was documented to be above the knee, which would not be typical of either sickle cell or venous ulcers. Finally, patient care episodes were excluded from analyses if they had missing data for key variables within the analysis. In total, 3,464 sickle cell and venous ulcers were excluded. When a patient was lost to follow-up for over 30 days and then returned for care, this was considered a new care episode, as no data were available for ulcer progression during the period of loss to follow-up and the patient was out of care during that time.

For all analyses, deidentified data were extracted using SQL software and analyzed using Stata/MP 14.1 (StataCorp, College Station, TX). Descriptive statistics were used to illustrate the distribution of key characteristics in this population. To describe characteristics of sickle cell and venous ulcers and to determine predictors of healing for sickle cell ulcers, the study used $\chi^{2}$ - and $t$-test, Kaplan-Meier curves, and multivariate logistic regression.

All data included in the analyses were fully deidentified secondary data and were exempt from review as determined by Quorum Review IRB. 


\section{RESULTS}

\section{Identification of sickle cell ulcers}

To evaluate the accuracy of documented clinical diagnosis of sickle cell ulcers, ICD-9 and ICD-10 coding for sickle cell disease was reviewed for all included patients with sickle cell ulcers. All patients with a clinical diagnosis of sickle cell ulcer also had an ICD-9 or ICD-10 code indicating sickle cell disease, confirming the diagnosis. The most frequently occurring codes were 282.6 ("sickle cell disease, unspecified") for ICD-9 and D57.1 ("sicklecell disease without crisis") for ICD-10.

At least one sickle cell ulcer patient was identified in 114 of the 794 wound care centers (14\%), with a range of 1-14 care episodes per center during the study period. Patients in the sample came from 32 states.

\section{Comparison of full sample and subsample}

The final full sample included 133 unique sickle cell patients with 427 wounds, for whom there were 198 care episodes. There were also 83,041 unique venous ulcer patients with 203,797 wounds for whom there were 97,547 care episodes.

The subsample of data obtained from complete electronic medical records included 149 sickle cell care episodes (75.3\% of all 198 sickle cell care episodes) and 69,349 venous ulcer care episodes $(71.1 \%$ of all 97,547 venous ulcer care episodes). There were no significant variations between wounds in the full sample and those in the subsample based on an analysis of patient age, comorbid disease, and wound characteristics.

\section{Patient characteristics in care episodes for sickle cell ulcers versus venous ulcers}

Patients with sickle cell disease presenting for care demonstrated a statistically significant younger age than those with venous ulcers (Fig. 1A), with mean age of 42.2 years compared with 70.6 years $(p<0.001)$, and were more likely to be male $(59.6 \%$ vs. $51.5 \%, p<0.05)$. Patients with sickle cell ulcers had a similar number of individual ulcers during a care episode to those presenting with venous ulcers ( 2.2 vs. $2.1, p=0.51$ ).

Information on comorbid medical conditions was obtained from the more complete medical records included in the subsample analysis. The i-heal system allows for recording of up to 25 comorbid conditions. However, because the medical history is not a required field in i-heal, and many centers concurrently document in a general electronic health record, it is likely that comorbid conditions are underreported. Patients with sickle cell ulcers had fewer recorded comorbid conditions (1.42 vs.
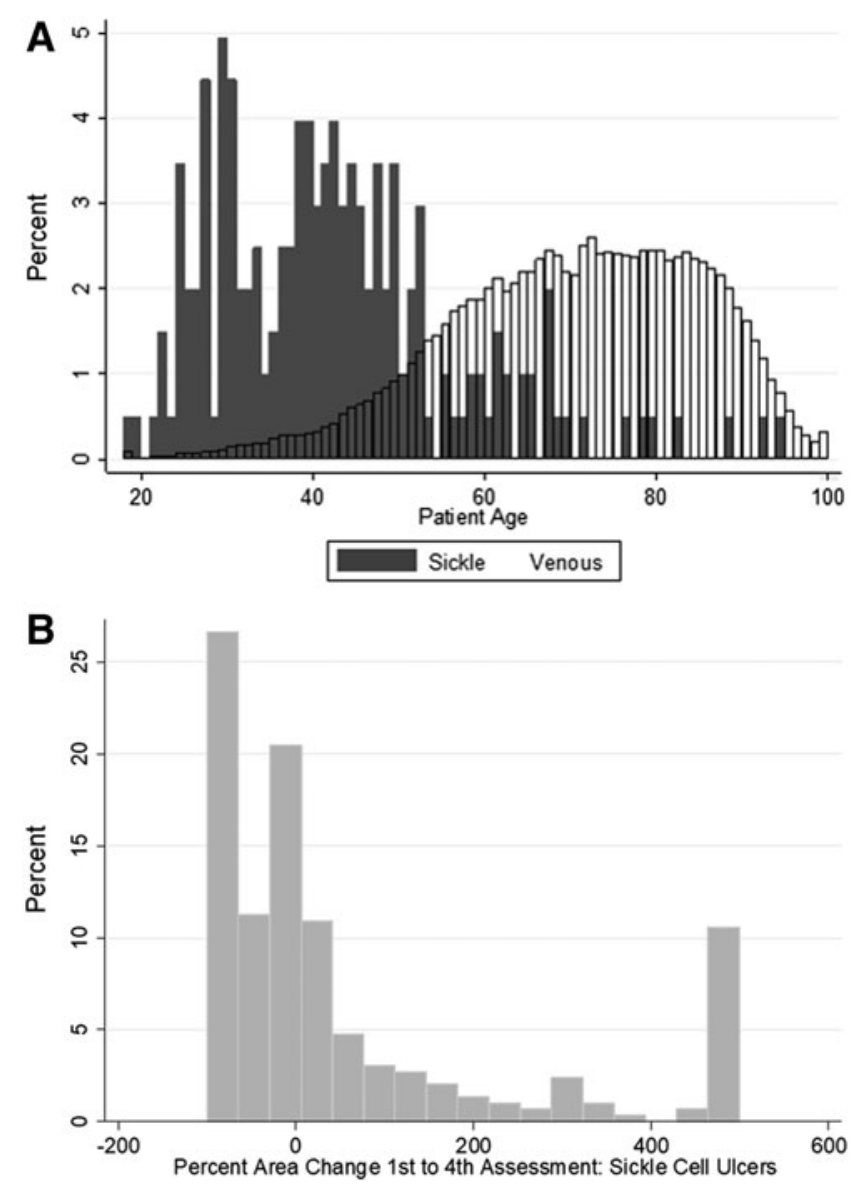

Figure 1. (A) Distribution of patient age at presentation for patients with sickle cell ulcers and venous ulcers. (B) Distribution of the change in wound area between first and fourth assessments in sickle cell ulcers.

$2.33, p<0.001)$. They had lower rates of type II diabetes $(1.4 \%$ vs. $31.0 \%, p<0.001)$, congestive heart failure $(3.4 \%$ vs. $10.7 \%, p<0.01)$, hypertension ( $10.1 \%$ vs. $37.5 \%, p<0.001)$, and peripheral venous disease $(3.4 \%$ vs. $11.2 \%, p<0.01)$ than patients with venous ulcers. There was also a nonstatistically significant trend toward less end-stage renal disease (1.3\% vs. $2.0 \%, p=0.57)$ and peripheral arterial disease $(1.3 \%$ vs. $3.5 \%, p=0.152)$ in the sickle cell population compared with the venous ulcer group.

\section{Wound characteristics, utilization patterns, and healing rates}

Table 1 displays the descriptive characteristics of sickle and venous ulcers at time of presentation, as well as their utilization of wound healing center services. Despite being smaller in area at presentation, sickle cell ulcers that had been present for longer before initial assessment, were less likely to heal, healed more slowly, and were followed up in clinic for longer periods of time compared with 
Table 1. Characteristics of sickle cell ulcers compared with venous ulcers

\begin{tabular}{|c|c|c|c|c|c|c|c|}
\hline & \multicolumn{3}{|c|}{ Sickle Cell Ulcers } & \multicolumn{3}{|c|}{ Venous Ulcers } & \multirow[b]{2}{*}{$\mathrm{p}$} \\
\hline & Mean/\% & $S E$ & $S D$ & Mean/\% & $S E$ & $S D$ & \\
\hline Ulcer duration at time of initial assessment (days) & 88.95 & 6.25 & 129.2 & 52.92 & 0.21 & 90.76 & $<0.001$ \\
\hline Depth at first assessment $(\mathrm{cm})$ & 0.17 & 0.01 & 0.21 & 0.15 & 0 & 0.22 & $<0.05$ \\
\hline Area at first assessment $\left(\mathrm{cm}^{2}\right)$ & 8.54 & 0.75 & 15.55 & 11.57 & 0.05 & 22.75 & $<0.001$ \\
\hline Foot (including ankle) (\%) & 69.75 & & & 12.08 & & & $<0.001$ \\
\hline Lower leg (\%) & 27.25 & & & 87.20 & & & \\
\hline Toe $(\%)$ & 3.00 & & & 0.69 & & & \\
\hline Days between first and last assessment & 64.55 & 3.14 & 64.91 & 44.41 & 0.12 & 55.38 & $<0.001$ \\
\hline Number of assessments & 8.21 & 0.42 & 8.71 & 6.65 & 0.02 & 7.83 & $<0.001$ \\
\hline Number of debridements & 4.43 & 0.31 & 6.31 & 3.02 & 0.01 & 5.02 & $<0.001$ \\
\hline Percent area change between first and fourth assessments $(\%)^{* *}$ & +58.25 & 10.83 & 184.75 & -13.02 & 0.39 & 134 & $<0.001$ \\
\hline Percentage healed at final clinic assessment & 59.35 & & & 77.26 & & & $<0.001$ \\
\hline
\end{tabular}

SD, standard deviation; $S E$, standard error.

${ }^{* *} p<0.01$.

venous ulcers. Patients with sickle cell disease had more total clinic visits and debridements than patients with venous ulcers. However, this may be explained by the longer length of time for which they were in treatment. The overall frequency of visits and debridements was similar for the two groups (clinic visits every 7.9 days for sickle cell ulcers compared with 6.7 days for venous ulcers; debridements every 14.6 days for sickle cell ulcers, compared with 14.7 days for venous ulcers).

Of ulcers that did heal during the episode of care, sickle cell ulcers took a mean of 67.1 days (median of 49 days), and venous ulcers took a mean of 44.7 days (median 28 days) $(p<0.001)$.

Of the 433 sickle cell ulcers, data on change in area between first and fourth assessment were available for 293 wounds. Within this group, 166 (43\%) increased in area during this time period. By contrast, only $13 \%$ of venous ulcers increased in area. On average across the 293 wounds, the sickle cell ulcers increased in area by $58.25 \%$ between the first and fourth assessments. The distribution of change in area between the first and fourth assessments in sickle cell ulcers is illustrated in Fig. 1B.

\section{Patterns of healing}

Logistic regression was used to explore characteristics of sickle cell ulcers at initial presentation that were associated with healing. Duration of wound $>90$ days $(\mathrm{OR}=0.36, p<0.001)$ showed significant negative association, as did larger wound areas (area $>5$ and $\leq 10 \mathrm{~cm}^{2}[\mathrm{OR}=0.40, p=0.008]$ and area $>10 \mathrm{~cm}^{2}[\mathrm{OR}=0.25, p<0.001]$; area $>2$ and $\leq 5 \mathrm{~cm}^{2}$ $[\mathrm{OR}=0.67, p=0.163]$ was not significantly associated, compared with area $\leq 2 \mathrm{~cm}^{2}$ ). Patients' age and sex were not significantly associated with healing.

As illustrated in Fig. 2, Kaplan-Meier curves demonstrate slower healing for sickle cell ulcers than for venous ulcers across categories of prior
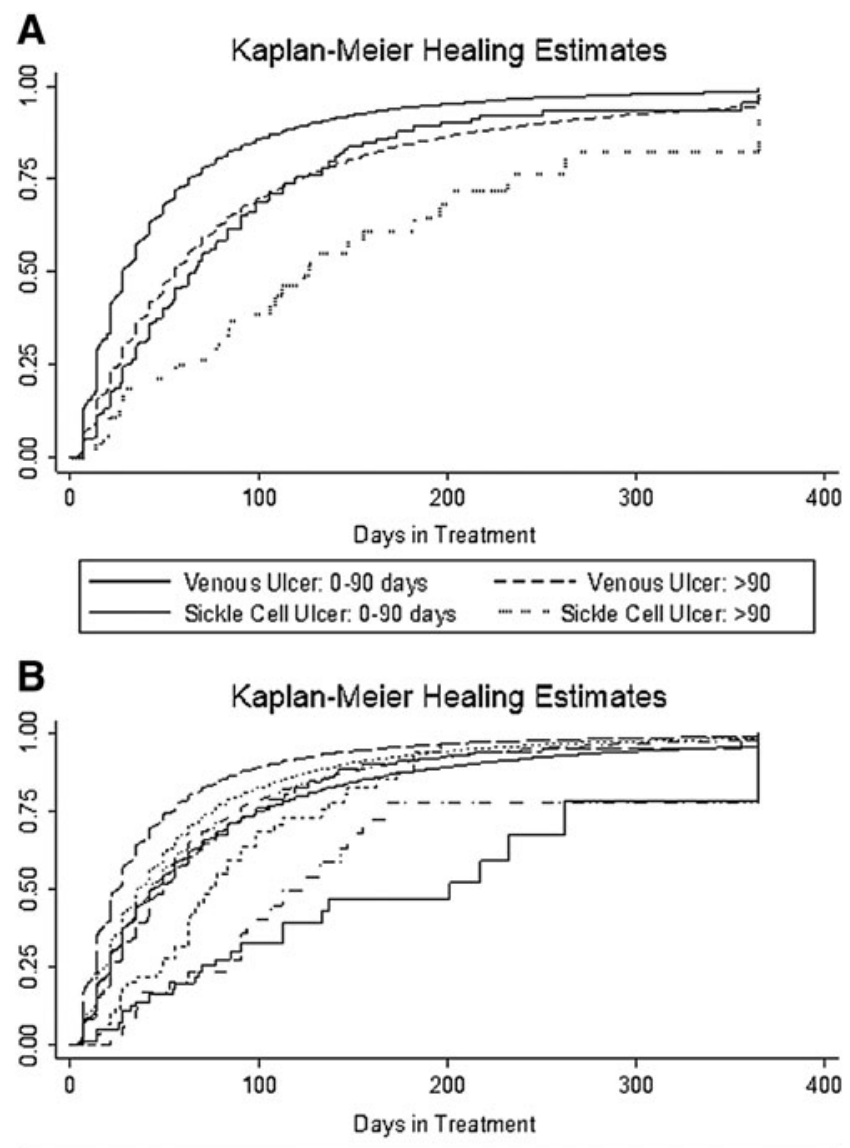

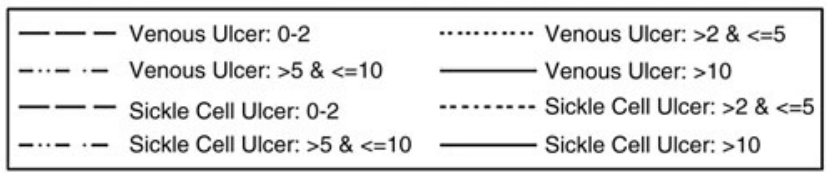

Figure 2. (A) Kaplan-Meier healing curve of sickle cell ulcers and venous ulcers, by duration of wound at time of first assessment. (B) Kaplan-Meier healing curve of sickle cell ulcers and venous ulcers, by area of wound at time of first assessment. 
duration $\left(\chi^{2}=16.34\right.$ Log rank- $\left.p<0.001\right)$ and wound area $\left(\chi^{2}=8,190.96\right.$, Log rank- $\left.p<0.001\right)$.

\section{DISCUSSION}

We report an analysis of wound characteristics and clinical evolution in patients with sickle cell disease as distinct from patients with venous ulcers. This study leveraged a national network of electronic health records from wound treatment centers to create the largest data set of sickle cell ulcer patients analyzed to date in the published literature. Use of this data source resulted in a number of unique contributions to the knowledge of sickle cell ulcer characteristics and evolution.

Our analysis identified that duration over 90 days and wound area $>10 \mathrm{~cm}^{2}$ are predictors of poor outcome for sickle cell ulcers. This is consistent with previous studies, which were conducted within highvolume sickle cell disease referral centers, ${ }^{7,12}$ and confirms that these findings are applicable to a broader population treated in wound healing centers. Our findings confirmed a significant age difference between patients with sickle cell ulcers and those with venous ulcers, 42.2 years versus 70.7 years, respectively. The younger age of the sickle cell ulcer population highlights the high and potentially prolonged deleterious effect that these wounds have on the quality of life and functioning of patients in early- to mid-life and their families. $^{7,15}$ Kaplan-Meier curves illustrated that sickle cell ulcers had slower healing rates across all categories of duration and area compared with venous ulcers. Although area and duration at presentation are predictors of healing for both sickle cell ulcers and venous ulcers, this observation is useful to apply only within each wound etiology, not across different wound etiologies.

Furthermore, we showed that between the initial and the fourth clinic assessment, $43 \%$ of ulcers increased in surface area, with mean change in area being an increase of $58 \%$ across the entire group despite treatment. This increase in size occurred despite treatment at specialized wound healing centers that presumably use and follow standard of care guidelines. One possible explanation is that when the current standard of care for venous leg ulcers is applied to sickle cell ulcers, a partial response should be expected and may include an initial period of increase in area. Alternatively, the sickle cell ulcers that respond to treatment may be intrinsically different from those that do not decrease in size and may be unlikely to heal with traditional therapies. The concept of multiple phenotypes of sickle cell ulcers has been previously postulated based on clinical observations. ${ }^{10}$ In brief, it was proposed that there is a "one-time" ulcer, which occurs at a young age, often following minimal trauma, heals within several months with most types of wound care, and usually does not recur; a "stuttering ulcer," which is small, heals and recurs for many years; and a "longstanding" ulcer, often presenting in older individuals, which takes years to heal or does not heal and leads to severe bony deformities. The increase in wound area after presentation for care may be an illustration that current standards of wound care are ineffective, or only partially effective in altering the natural course of stuttering and longstanding ulcers. Future prospective studies will be needed to explore these hypotheses.

In this study, patients with sickle cell ulcers were in treatment for longer than venous ulcer patients in each care episode (mean of 64.55 vs. 44.41 days between first and last assessment), and yet were more likely to re-present to a wound center for additional care episodes (198 care episodes for 133 unique sickle cell patients or mean 1.49 episodes per patient, compared with 97,547 care episodes for 83,041 unique venous ulcer patients or mean 1.17 care episodes per patient). This suggests that patients with sickle cell ulcers were more likely to experience recurrent ulcers, and/or they were more likely to drop out of care for at least 30 days, and then re-present for additional care. These utilization patterns show that sickle cell ulcer patients are accessing wound healing center services intensively compared with their counterparts with venous ulcers, despite poorer healing. A similar frequency of clinic visits and debridements suggests that wound healing centers are applying treatment protocols that were based on evidence for venous ulcers to the sickle cell ulcer population, even though there is a lack of evidence for effectiveness in this group. The later presentation of sickle cell ulcers compared with venous ulcers (with mean prior duration of 88 days compared with 58 days) may indicate barriers to care such as delayed referral, or could be related to re-presentation by patients who had previously accessed care.

Study limitations were primarily a consequence of retrospective use of clinical data. Many variables of potential interest in studying sickle cell ulcers were not available in this database, or were of very poor quality to be usable. Although the data set did include frequency of visits and of debridements, additional data on treatment approaches for sickle cell ulcers-such as topical treatments, compression therapy, human skin equivalents, skin grafts, transfusion therapy, nutritional support, antibiot- 
ics, or pentoxifylline-were not available. ${ }^{9,12}$ The analysis focused on healing within individual care episodes, and could not discern between wound recurrence and wound persistence. Finally, the analysis does not clarify to what degree larger area and longer duration at presentation are markers for intrinsically poorer healing processes in the patient, as opposed to markers of poor or delayed initiation of care that leads to worse healing prognosis.

This analysis suggests future pathways for research to improve understanding of the pathophysiology of sickle cell ulcers and develop an evidence base for treatment. Little evidence exists for specific treatments for sickle cell ulcers, and it is unknown if the "bundle" of wound care provided at treatment centers or through home care have any effect on prognosis. Well-designed studies are therefore needed to improve care for these patients. This analysis also highlights the importance of controlling for baseline prognosis in studies of sickle cell ulcer healing. The effect on baseline prognosis of wound characteristics on presentation, including size and prior duration of wound, should be taken into account in the design of treatment trials.

\section{INNOVATION}

This analysis suggests that a national network of electronic health records from wound treatment centers can effectively identify a large number of patients with sickle cell ulcers within a broader population of patients than those seen at major referral centers. This approach could support further large-scale studies focusing on epidemiology, healing patterns, utilization, and treatment, and will benefit from improved data collection as information technology systems evolve. Collaboration with a network of wound healing centers could support identification and recruitment of sickle cell ulcer patients for prospective studies, including treatment trials and studies requiring tissue samples.

\section{ACKNOWLEDGMENT AND FUNDING SOURCES}

The authors are thankful to Elena H. Crouch, BS for expert editorial assistance.

\section{AUTHOR DISCLOSURE AND GHOSTWRITING}

No competing financial interests exist. The content of this article was expressly written by the authors listed. No ghostwriters were used to write this article.

\section{ABOUT THE AUTHORS}

Anna Flattau, MD, MSc, MS, is Vice Chair for Clinical Services in the Department of Family and Social Medicine at Montefiore Medical Center. Hanna Gordon, PhD, is Executive Director of Research and Informatics at Healogics. Giacomo Vinces, MD, is an attending physician with the Wound Healing Program at Montefiore Medical Center. William J. Ennis, DO, is Professor of Surgery and Chief of the Section of Wound Healing and Tissue Repair at the University of Illinois at Chicago. Caterina P. Minniti, MD, is Professor of Medicine and Pediatrics at Albert Einstein College of Medicine and Director of the Sickle Cell Center for Adults at Montefiore Medical Center.

\section{REFERENCES}

1. Chaturvedi S, DeBaun MR. Evolution of sickle cell disease from a life-threatening disease of children to a chronic disease of adults: the last 40 years. Am J Hematol 2016;91:5-14.

2. Powars DR, Chan LS, Hiti A, Ramicone E, Johnson C. Outcome of sickle cell anemia: a 4-decade observational study of 1056 patients. Medicine (Baltimore) 2005;84:363-376.

3. Minniti CP, Taylor JG, Hildesheim M, O'Neal P, Wilson J, Castro 0, et al. Laboratory and echocardiography markers in sickle cell patients with leg ulcers. Am J Hematol 2011;86:705-708.
4. Alavi A, Kirsner RS. Hemoglobinopathies and leg ulcers. Int J Low Extrem Wounds 2015;14:213216.

5. Eckman JR. Leg ulcers in sickle cell disease. Hematol Oncol Clin North Am 1996;10:13331344. 
6. Trent JT, Kirsner RS. Leg ulcers in sickle cell disease. Adv Skin Wound Care 2004;17:410-416.

7. Halabi-Tawil M, Lionnet F, Girot R, Bachmeyer $C$, Lévy PP, Aractingi S. Sickle cell leg ulcers: a frequently disabling complication and a marker of severity. Br J Dermatol 2008;158:339-344.

8. Maximo C, Olalla Saad ST, Thome E, Queiroz AM, Lobo C, Ballas SK. Amputations in sickle cell disease: case series and literature review. Hemoglobin 2016:40:150-155.

9. Altman IA, Kleinfelder RE, Quigley JG, Ennis WJ, Minniti CP. A treatment algorithm to identify therapeutic approaches for leg ulcers in patients with sickle cell disease. Int Wound J 2016;13: 1315-1324.

10. Minniti CP, Kato GJ. Critical Reviews: how we treat sickle cell patients with leg ulcers. Am J Hematol 2016;91:22-30.

11. Martí-Carvajal AJ, Knight-Madden JM, MartinezZapata MJ. Interventions for treating leg ulcers in people with sickle cell disease. Cochrane Database Syst Rev 2014:CD008394.

12. Senet $P$, Blas-Chatelain $C$, Levy $P$, et al. Factors predictive of leg-ulcer healing in sickle cell disease: a multicentre, prospective cohort study. $\mathrm{Br} \mathrm{J}$ Dermatol 2017;177:206-211.
13. Serena TE, Fife CE, Eckert KA, Yaakov RA, Carter MJ. A new approach to clinical research: integrating clinical care, quality reporting, and research using a wound care network-based learning healthcare system. Wound Repair Regen 2017;25:354-365.

14. Carter MJ. Harnessing Electronic Healthcare Data for Wound Care Research: wound Registry Analytic Guidelines for Less-biased Analyses. Wound Repair Regen 2017;25:564-573.

15. Edwards CL, Scales MT, Loughlin C, Bennett GG, Harris-Peterson S, De Castro LM, et al. A brief review of the pathophysiology, associated pain, and psychosocial issues in sickle cell disease. Int J Behav Med 2005:12:171-179. 